\title{
Estimation and characterization of PCDD/Fs and dioxin-like PCB emission from secondary zinc and lead metallurgies in China
}

\author{
Received 20th October 2008, Accepted 9th January 2009 \\ First published as an Advance Article on the web 6th February 2009 \\ DOI: $10.1039 / \mathrm{b818555g}$
}

Te Ba, Minghui Zheng, * Bing Zhang, Wenbin Liu, Guijin Su and Ke Xiao

Secondary zinc and lead production is addressed as one of the potential sources of polychlorinated dibenzo- $p$-dioxins and dibenzofurans (PCDD/Fs) and dioxin-like polychlorinated biphenyls (dioxinlike PCBs) due to the impurity of the raw material. However, the release inventory of PCDD/Fs and dioxin-like PCBs is very scarce for these secondary nonferrous metallurgies. This study selected typical secondary zinc and lead plants to investigate the emissions of PCDD/Fs and dioxin-like PCBs released from such plants in China. The toxic equivalent quantity (TEQ) emission factor of PCDD/Fs and dioxin-like PCBs released into the environment is higher for secondary zinc production, at $52298.02 \mathrm{ng}$ TEQ ton $^{-1}$ than for secondary lead production, at $646.05 \mathrm{ng}$ TEQ ton $^{-1}$. The most abundant congeners of PCDD/Fs are 2,3,4,7,8-PeCDF and 1,2,3,4,6,7,8-HpCDF for the secondary zinc and lead metallurgies, respectively. The most abundant congener of dioxin-like PCBs in the samples collected from both metallurgies is CB-126. According to the distribution of PCDD/Fs (PCDF/PCDD $\gg 1$ ) and the dominant contribution of higher chlorinated congeners, the de novo synthesis is assumed to be the main formation pathway of PCDD/Fs in the secondary zinc metallurgies. For the secondary lead metallurgies, the role of precursor formation is also very important. Based on the emission factor and production level, the total estimated emission amounts of PCDD/Fs and dioxin-like PCBs in both stack gas and fly ash released into the environment from secondary zinc and lead production is estimated to

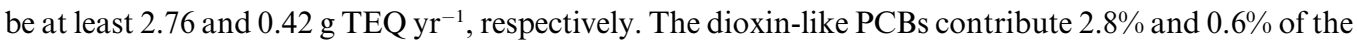
total emission from secondary zinc and lead plants, respectively.

\section{Introduction}

Polychlorinated dibenzo-p-dioxins and dibenzofurans (PCDD/ Fs) are known to be some of the most toxic pollutants which could be produced as unintentionally produced persistent organic pollutants (UP-POPs) in many industrial processes. ${ }^{1}$ Measures have to be taken to reduce the total releases of UPPOPs derived from anthropogenic sources, with the final goal being ultimate elimination. ${ }^{2}$

In recent years, there has been growing concerns around the UP-POPs inventory of metallurgy industries, especially the iron and steel metallurgy industry. ${ }^{3-6}$ However, information on the emission of UP-POPs from secondary nonferrous metal metallurgies is not enough although some conditions in the smelting process are suitable for formation of UP-POPs. These suitable conditions could be generally considered to be: (i) the elemental chlorine residing in the raw materials such as PVC, (ii) some types of nonferrous metal which could catalyze formation of UPPOPs, (iii) the proper temperature and oxygen concentration for formation of UP-POPs in some steps of the smelting process of secondary nonferrous metallurgy. ${ }^{1,7}$

Although the smelting process in the secondary nonferrous metal metallurgy is addressed as one pathway in the formation of some UP-POPs, very little data about UP-POP emissions exist for the secondary zinc and lead metallurgies, this is probably due to

State Key Laboratory of Environmental Chemistry and Ecotoxicology, Research Center for Eco-Environmental Sciences, Chinese Academy of Sciences, P.O. Box 2871, Beijing, 100085, China. E-mail: zhengmh@ rcees.ac.cn; Fax: +8610 62923563; Tel: +861062849172 their lower production level in comparison to some other metals such as copper and aluminium. ${ }^{1}$ Moreover, the data about emissions of dioxin-like PCBs from these secondary nonferrous metallurgies is not as common as that of PCDD/Fs. As part of a national UP-POP emissions inventory, this study focused on secondary zinc and lead production in China. The production levels of the secondary zinc and lead production in 2007 are 53000 and 682000 tons, respectively. Among the secondary lead plants, there are about 3 medium scale plants which contribute $3.3 \%$ to the total secondary lead yield in China. For the secondary zinc plants, the proportion of medium-sized enterprises is about $25 \%$ of the total secondary zinc yield in China. ${ }^{8}$ Based on the primary survey, two typical medium scale plants, with the necessary pollution control equipment, were selected from the secondary zinc and lead metallurgies in this study. The source-oriented method was adopted in the investigation of the emission of PCDD/Fs and dioxin-like PCBs from the secondary zinc and lead production. The calculation of total emission amounts is based on the emission factor achieved from the selected two plants and the production level of the secondary zinc and lead industries in China in 2007.

\section{Materials and method}

The smelting process of the secondary zinc production consists of feeding, melting, refining and casting in a crucible. For the secondary lead production, the smelting process consists of feeding, fusion, deoxidation, content adjusting, treatment of lead liquid and casting. The sampling in two types of metallurgies covered every step of the smelting process. The feeding and 
melting steps of secondary zinc production, as well as feeding and fusion steps of secondary lead production, got more attention because there are more organic parts containing residual chlorine in these steps than the latter steps.

For each plant, three stack gas samples and two fly ash samples were collected. Every stack gas sample from secondary zinc production corresponds to an entire smelting process. For secondary lead production, the first to third stack gas samples deal with the different steps and correspond to the feeding and fusion, treatment of lead liquid and casting, deoxidation and content adjusting. The sampling of stack gas was based on European method EN 1948 using an automatic isokinetic sampling system Isostack Basic (TCR TECORA, Italy). All the samples were collected in an upstream bag filter. Prior to collection, $\mathrm{O}_{2}, \mathrm{CO}_{2}, \mathrm{H}_{2} \mathrm{O}$ and $\mathrm{CO}$ levels in the stack gas were measured to calculate the composition of the stack gas using flue gas analyzer GA-12 plus (Madur, Austria). The particles in the stack gas were trapped by a filter ( $25 \mathrm{~mm}$ id, $90 \mathrm{~mm}$ length) when the stack gas passed through the filter. The filter is made from a silica glass microfiber thimble bought from Whatman International Ltd (Whatman, UK). After a condensing system, the gas was adsorbed by a trap with amberlite XAD-2 resin purchased from Supleco International Ltd (VARINA, USA). According to the method EN-1948, isotope dilution techniques were used in this study. Before sampling, the resin was spiked with ${ }^{13} \mathrm{C}_{12}$-labelled surrogate standards to ensure the accuracy of the sampling. The fly ash samples were collected from the bag filter and/or quenching tower outlet during the stack gas sampling.

Both the stack gas and fly ash samples were spiked with a mixture of ${ }^{13} \mathrm{C}_{12}$-labelled $\mathrm{PCDD} / \mathrm{Fs}$ and dioxin-like PCBs internal standards. The glass fiber filter and XAD-2 resin underwent Soxhlet extraction with toluene for $24 \mathrm{~h}$. The fly ash samples were pretreated selectively with $2 \mathrm{M} \mathrm{HCl}$, dried by air and underwent Soxhlet extraction with toluene for $24 \mathrm{~h}$. Then, the extract was cleaned up by a concentrated sulfuric acid gel column, a multi-layer silica gel column and an alumina column. Before HRGC/HRMS analysis, the samples were spiked separately with ${ }^{13} \mathrm{C}_{12}$-labelled $\mathrm{PCDD} / \mathrm{Fs}$ and dioxin-like PCBs recovery standards. HRGC/HRMS measurements were carried out with a Hewlett-Packard Model 6890 gas chromatograph coupled with an AutoSpec Ultima mass spectrometer (Waters, USA). For analysis of PCDD/Fs and dioxin-like PCBs, a DB-5 capillary column $(60 \mathrm{~m}, 0.25 \mathrm{~mm}, 0.20 \mu \mathrm{m}$, Agilent $\mathrm{J} \& \mathrm{~W})$ was used. All dioxin-analytical grade solvents were purchased from Fisher Company (Thermo Fisher, USA). PCDD/F and dioxinlike PCB standards, including ${ }^{13} \mathrm{C}_{12}$-labeled homologues, were purchased from Wellington Laboratories (Ontario, Canada). For all determinations in this study, recovery of the internal standard was over $60 \%$, proving the validity of the sample treatment; recovery of the surrogate spike was in the range of 70$80 \%$, proving the high efficiency of gas sampling in this study.

\section{Results and discussion}

\subsection{Characterization of PCDD/Fs emission from the secondary zinc and lead metallurgies}

3.1.1 Congener profiles of PCDD/Fs in stack gas and fly ash of secondary zinc and lead metallurgies. The concentration homologue distributions of PCDD/Fs in stack gas of secondary zinc and lead metallurgies are shown in Fig. 1. The stack gases 13 represent the 3 samples in the smelting processes of secondary zinc and lead metallurgies. For samples from secondary zinc plants, the figure named by 'gas average' depicts the average value of the three parallel samples. The pictures named by 'gas total' depict the integrated results of the whole processes of secondary lead smelting because the three samples are collected in different steps of the smelting process. It could be observed that the difference between the homologue distributions in the secondary zinc and lead metallurgies is obvious. In the stack gas from secondary zinc production, tetra-CDD/Fs (TeCDD/Fs) and penta-CDD/Fs (PeCDD/Fs) make the most important contribution to the concentration. However, for secondary lead production, the higher chlorinated $\mathrm{PCDD} / \mathrm{Fs}$ like octa-CDD/Fs (OCDD/Fs) are the dominant homologues. Furthermore, in the fly ash from the secondary zinc and lead production, TeCDD/Fs and $\mathrm{OCDD} / \mathrm{Fs}$ make the most important contribution to the concentration, respectively.

Fig. 2 presents the ratios of PCDF/PCDD $\left(R_{\mathrm{DF} / \mathrm{DD}}\right)$ in stack gas and fly ash from the secondary zinc and lead metallurgies. For the formation of PCDD/Fs in large scale thermal processes, two major mechanisms have been proposed, i.e. pyrosynthesis or precursor formation and de novo synthesis. If the PCDF/PCDD ratio exceeds 1 , the de novo synthesis may be the main formation mechanism of PCDD/Fs. ${ }^{10}$ It could be seen that the $R_{\mathrm{DF} / \mathrm{DD}}$ from tetra to octa $\mathrm{CDD} / \mathrm{Fs}$ in the stack gas from secondary zinc production decreases from 2.06 to 0.34 . The $R_{\mathrm{DF} / \mathrm{DD}}$ from Pe- to OCDD/Fs are close to or lower than 1 . In contrast, $R_{\mathrm{DF} / \mathrm{DD}}$ from Te- to OCDD/Fs in the stack gas from secondary lead production increases from 2.09 to 15.92 , and all of the $R_{\mathrm{DF} / \mathrm{DD}}$ are higher than 1 . Generally, the integrated $R_{\mathrm{DF} / \mathrm{DD}}$ of the secondary zinc and lead production are 1.23 and 8.76 , respectively. The $R_{\mathrm{DF} / \mathrm{DD}}$ of secondary lead production is higher than those obtained from other large scale thermal processes, such as incineration of municipal solid waste with the $R_{\mathrm{DF} / \mathrm{DD}}$ of 1.7 and wood combustion with the $R_{\mathrm{DF} / \mathrm{DD}}$ of 1.3 , but lower than average $R_{\mathrm{DF} / \mathrm{DD}}$ of 9.5 in secondary nonferrous metallurgies., ${ }^{3,9,10}$ Moreover, the different trends of $R_{\mathrm{DF} / \mathrm{DD}}$ in the fly ash from two types of metallurgies could be also observed from Fig. 2. $R_{\mathrm{DF} / \mathrm{DD}}$ in fly ash from the secondary zinc metallurgy decreases from Te- to $\mathrm{O}$ $\mathrm{CDD} / \mathrm{Fs}$, and the OCDF/OCDD ratio is lower than 1 . However, for the fly ash from the secondary lead metallurgy, the $R_{\mathrm{DF} / \mathrm{DD}}$ firstly decreases from Te- to $\mathrm{HxCDD} / \mathrm{Fs}$ and then rises from $\mathrm{Hx}-$ to $\mathrm{ODD} / \mathrm{Fs}$, and all the $R_{\mathrm{DF} / \mathrm{DD}}$ are higher than 3 .

The degrees of chlorination have been used to analyze the fingerprints of samples. ${ }^{10}$ It equals the sum of the product of the concentration percentage of the homologue multiplying the numbers of the substituted chlorine of the homologue. Fig. 3 shows that the chlorination degrees of PCDD/Fs vary from 4.66 ( $\mathrm{Zn}$ gas) to $7.34(\mathrm{~Pb}$ gas) in stack gas and fly ash from the secondary zinc and lead metallurgies. Such a high value of 7.34 for the chlorination degree in the stack gas from the secondary lead production further indicates that the concentration distributions of PCDD/Fs in the secondary lead metallurgy are dominated by higher chlorinated homologues.

3.1.2 TEQ of PCDD/Fs in stack gas and fly ash from the secondary zinc and lead metallurgies. Fig. 4 shows the mean TEQ 

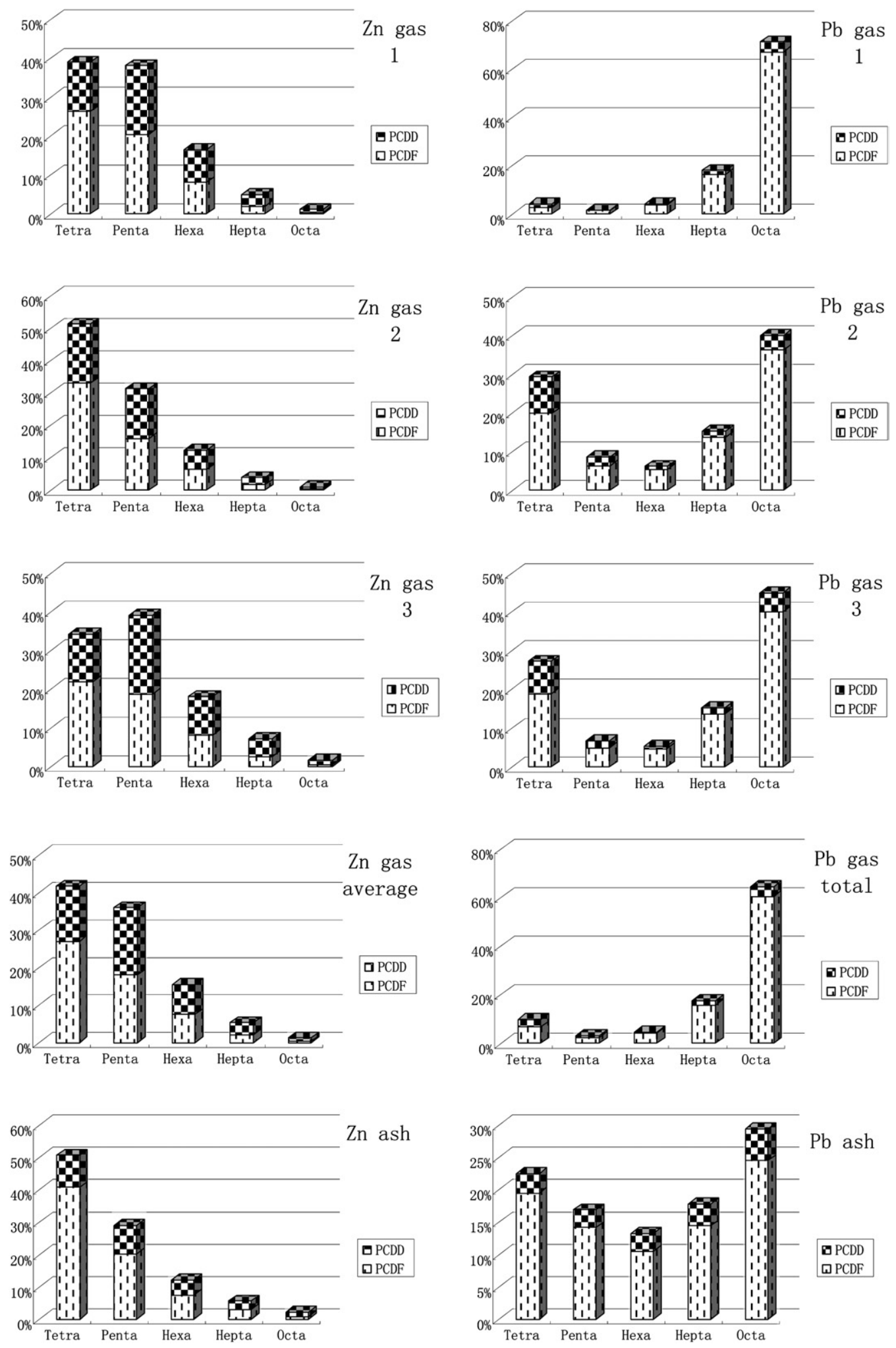

Fig. 1 The percentage contributions of homologue to the total concentration from TeCDD/Fs to OCDD/Fs in stack gas and fly ash from secondary zinc and lead metallurgies.

of PCDD/Fs in stack gas and fly ash samples collected from the secondary zinc and lead plants. The average TEQs of stack gas released from the secondary zinc and lead metallurgy are 98.02 and $0.35 \mathrm{ng}$ TEQ $\left(\mathrm{N} \mathrm{m}^{3}\right)^{-1}$, respectively. The corresponding TEQ ranges vary respectively from 78.98 to $153.88 \mathrm{ng}$ TEQ $\left(\mathrm{N} \mathrm{m}^{3}\right)^{-1}$ and from 0.053 to $0.727 \mathrm{ng}$ TEQ $\left(\mathrm{N} \mathrm{m}^{3}\right)^{-1}$. The mean TEQ of fly 

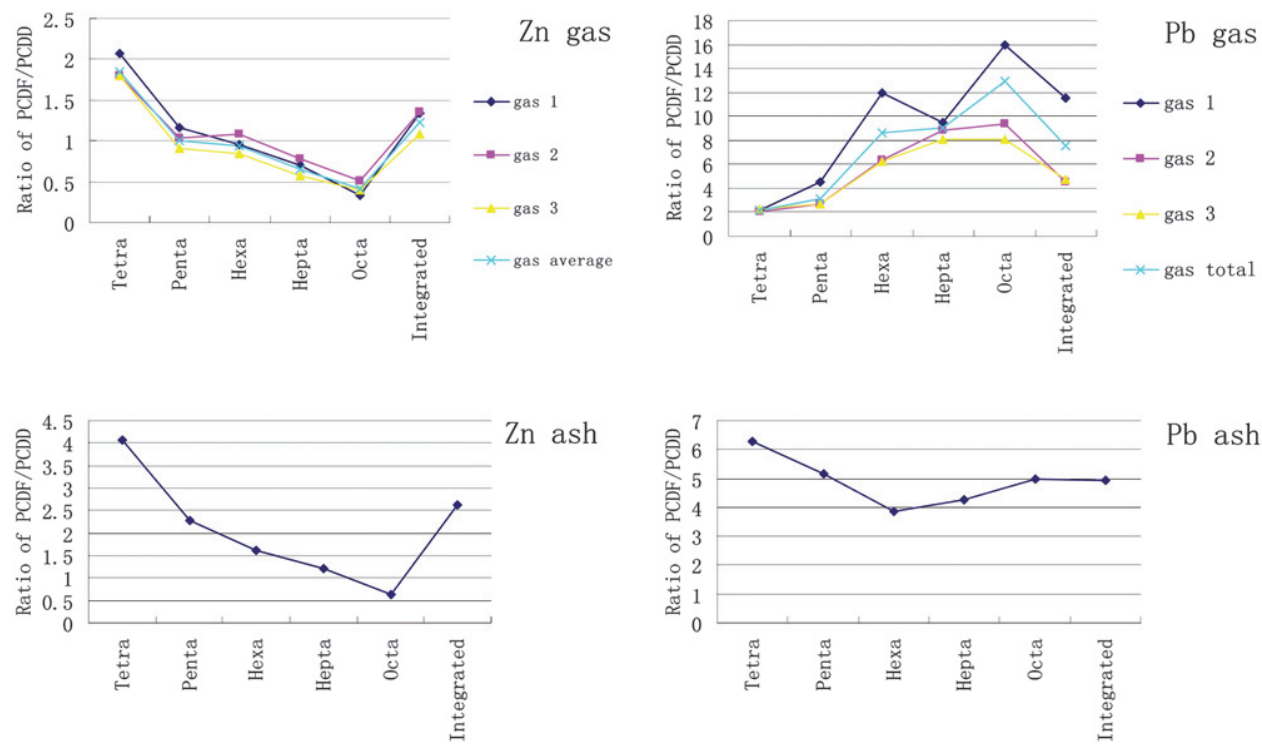

Fig. 2 Concentration ratios of PCDF to PCDD $\left(R_{\mathrm{DF} / \mathrm{DD}}\right)$ in stack gas and fly ash from secondary zinc and lead metallurgies.

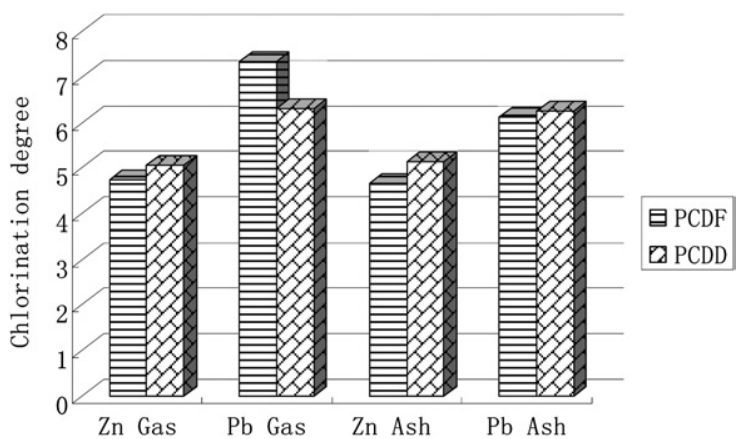

Fig. 3 Analysis of the homologue concentration chlorination degrees for Te- to OPCDD/Fs in stack gas and fly ash from the secondary zinc and lead metallurgies. ash samples is $5.64 \mathrm{ng}$ TEQ $\mathrm{g}^{-1}$ with a range of 4.66-6.62 $\mathrm{ng}$ TEQ $\mathrm{g}^{-1}$ for secondary zinc production, and is $0.05 \mathrm{ng}$ TEQ $\mathrm{g}^{-1}$ with a range of $0.04-0.06 \mathrm{ng}^{\mathrm{T}} \mathrm{TEQ} \mathrm{g}^{-1}$ for secondary lead production.

The TEQ congener patterns of PCDD/Fs in stack gas and fly ash are shown in Fig. 5. The abundance sequences are quite different for the samples from these two secondary metallurgies. The most abundant congener in stack gas from secondary zinc metallurgies is $2,3,4,7,8$-PeCDF (36.1\%), followed by $1,2,3,7,8$ PeCDD (26.8\%) and 2,3,7,8-TCDD (6.1\%). For secondary lead metallurgies the sequence is $1,2,3,4,6,7,8-\mathrm{HpCDF}(20.2 \%)$, followed by $2,3,4,6,7,8-\mathrm{HxCDF}(17.2 \%)$ and $2,3,4,7,8-\mathrm{PeCDF}$ $(16.3 \%)$. The patterns are different from those reported for secondary zinc and lead metallurgies in Korea, which may be caused by differences in raw material. ${ }^{9}$
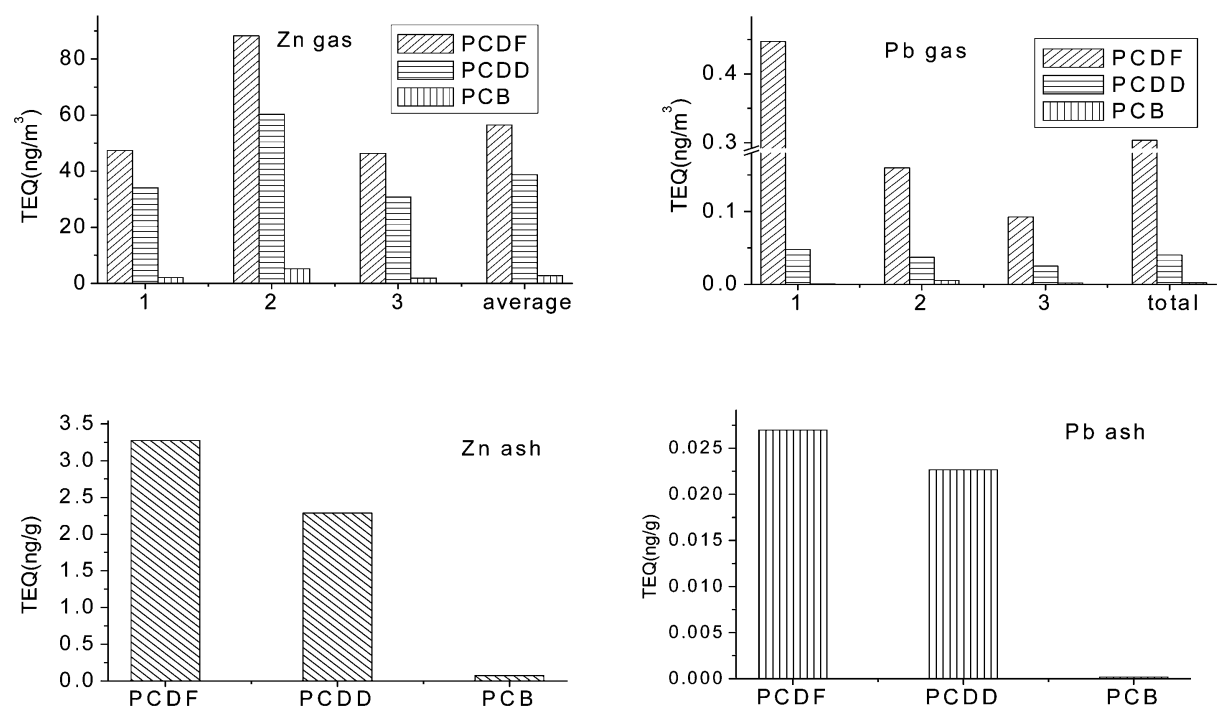

Fig. 4 The average level of PCDD/Fs and dioxin-like PCBs in TEQ format in stack gas and fly ash from the secondary zinc and lead metallurgies. 

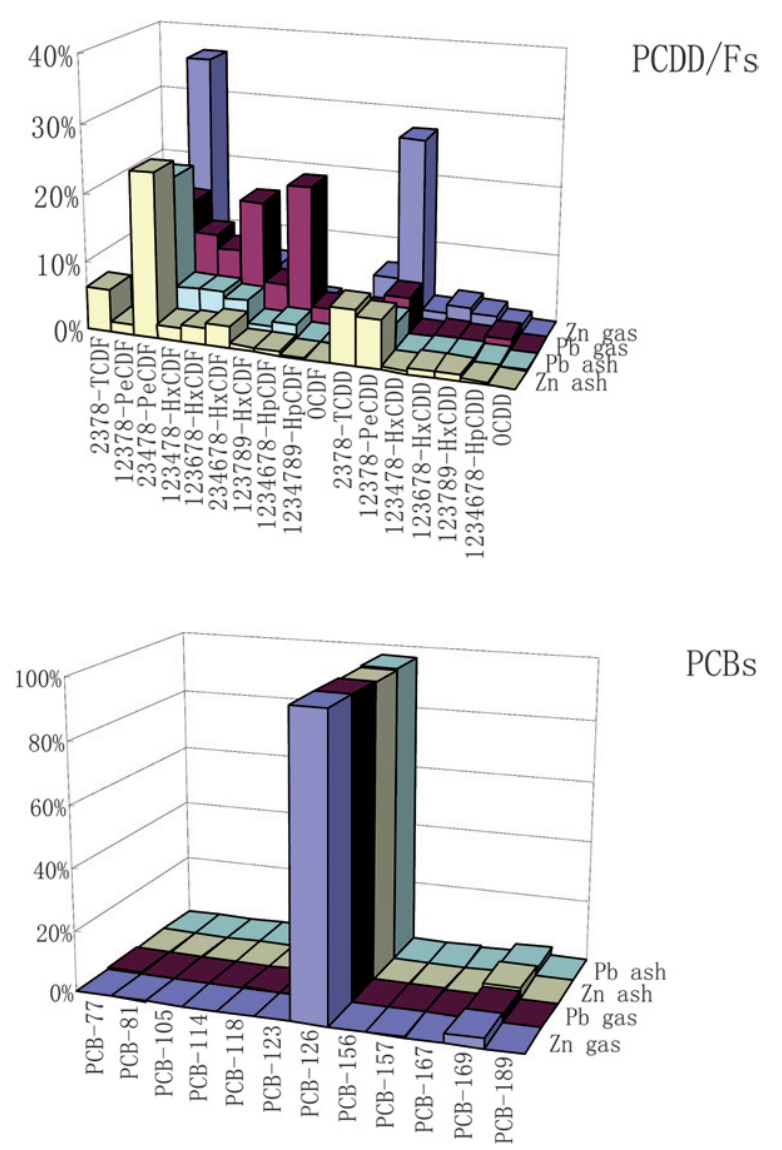

PCBs

Fig. 5 The TEQ percentage contribution of the congeners of PCDD/Fs and dioxin-like PCBs in stack gas and fly ash from the secondary zinc and lead metallurgies.

\subsection{Characterization of dioxin-like PCBs emission from secondary zinc and lead metallurgies}

3.2.1 TEQ of dioxin-like PCBs in stack gas and fly ash of the secondary zinc and lead metallurgies. The mean TEQ of dioxinlike PCBs in stack gas and fly ash of secondary zinc and lead metallurgies are also shown in Fig. 4. The average TEQs of dioxinlike PCBs in stack gas released from secondary zinc and lead metallurgy are 2.786 and $0.002 \mathrm{ng}$ TEQ $\left(\mathrm{N} \mathrm{m}^{3}\right)^{-1}$ respectively. The TEQ ranges of dioxin-like PCBs of samples from secondary zinc and lead production are from 1.9 to $5.28 \mathrm{ng}$ TEQ $\left(\mathrm{N} \mathrm{m}^{3}\right)^{-1}$ and from 0.0009 to $0.005 \mathrm{ng}$ TEQ $\left(\mathrm{N} \mathrm{m}^{3}\right)^{-1}$ respectively. The mean TEQ of dioxin-like PCBs of fly ash released from secondary zinc and lead production are 0.0725 and 0.0002 ng TEQ $\mathrm{g}^{-1}$, respectively. The TEQ ranges of dioxin-like PCBs of fly ash samples from secondary zinc and lead production are from 0.0329 to $0.1121 \mathrm{ng}$ TEQ $\mathrm{g}^{-1}$ and from 0.00007 to $0.0003 \mathrm{ng}^{\mathrm{TEQ}} \mathrm{g}^{-1}$, respectively.
3.2.2 Congener profiles of dioxin-like PCBs in stack gas and fly ash of secondary zinc and lead metallurgies. The TEQ congener patterns of dioxin-like PCBs in stack gas and fly ash of secondary zinc and lead production are shown in Fig. 5. The most abundant congener is $2,2^{\prime}, 3,3^{\prime}, 4-\mathrm{PeCB}$ (CB-126) in both metallurgies, followed by $2,2^{\prime}, 3,3^{\prime}, 4^{\prime}, 4-\mathrm{HxCB}$ (CB-169). The TEQ abundance ratios in the stack gas sample are $96.2 \%$ (zinc) and $96.3 \%$ (lead) for CB-126, and 3.1\% (zinc) and 2.4\% (lead) for CB-169. These two congeners together constitute more than $98 \%$ of total TEQ concentration of dioxin-like PCBs in stack gas samples. For fly ash, the most abundant congener is also CB-126 in both metallurgies, followed by CB-169. Their TEQ abundance ratios in fly ash are $96.1 \%$ (zinc) and $96.7 \%$ (lead) for CB-126, and 3.5\% (zinc) and $2.5 \%$ (lead) for CB-169. These two congeners together constitute more than $99 \%$ of total TEQ concentration of dioxinlike PCBs in fly ash samples.

In contrast to $\mathrm{PCDD} / \mathrm{Fs}$ congener patterns also shown in Fig. 5, the patterns of dioxin-like PCBs are very similar among four types of samples of stack gas and fly ash from secondary zinc and lead metallurgies. And the contribution of TEQ is attributed to almost one congener in all the samples collected. It resembles the result from Korea on dioxin-like PCBs emission from secondary zinc and lead metallurgies except that the contribution of CB-169 is higher. ${ }^{9}$ Additionally, this is also consistent with the studies on other thermal sources, such as municipal waste incineration, sintering and crematoriums. ${ }^{11}$

\subsection{TEQ emission amount (ng) of PCDD/Fs and dioxin-like PCBs from the selected secondary lead and zinc plants}

The emission amount of PCDD/Fs and dioxin-like PCBs in stack gas from secondary lead and zinc production is shown in Table 1. The emission amount of 3 samples from secondary zinc production is very similar due to the collection from three same smelting processes. By contrast, the data of 3 samples from secondary lead production are quite different amongst each other. The emission amount of the first sample collected from the feeding and fusion step is much higher than the other two, accounting for $79.1 \%$ of the total emission of PCDD/Fs and dioxin-like PCBs in the smelting process of secondary lead. The rather high value suggests that the feeding and fusion step should get much more attention for pollution control.

\subsection{The formation mechanism of PCDD/Fs and dioxin-like PCBs released from secondary zinc and lead metallurgies}

For the formation of PCDD/Fs in large scale thermal processes, two major mechanisms have been proposed, i.e. pyrosynthesis or precursor formation and de novo synthesis. In the secondary lead metallurgy, the PCDF/PCDD ratio exceeds 1 and the homologue

Table 1 Total TEQ emission amount (ng) of PCDD/Fs and dioxin-like PCBs from the selected secondary lead and zinc plants

\begin{tabular}{|c|c|c|c|c|c|c|c|c|}
\hline & $\begin{array}{l}\mathrm{Zn} \\
\text { gas } 1\end{array}$ & $\begin{array}{l}\mathrm{Zn} \\
\text { gas } 2\end{array}$ & $\begin{array}{l}\mathrm{Zn} \\
\text { gas } 3\end{array}$ & $\begin{array}{l}\mathrm{Zn} \\
\text { gas average }\end{array}$ & $\begin{array}{l}\mathrm{Pb} \\
\text { gas } 1\end{array}$ & $\begin{array}{l}\mathrm{Pb} \\
\text { gas } 2\end{array}$ & $\begin{array}{l}\mathrm{Pb} \\
\text { gas } 3\end{array}$ & $\begin{array}{l}\mathrm{Pb} \\
\text { gas total }\end{array}$ \\
\hline PCDF & 444836 & 591622 & 582480 & 539646 & 15068 & 2193 & 1254 & 18516 \\
\hline Dioxin-like PCB & 20569 & 35377 & 23924 & 26624 & 29.8 & 74.5 & 27.1 & 131 \\
\hline Total & 764655 & 995687 & 969513 & 909952 & 16680 & 2702 & 1594 & 20977 \\
\hline
\end{tabular}


and degree of chlorination in Fig. 1 and 3 point towards the dominant presence of higher chlorination homologues. These indicate that the de novo synthesis may be the main formation mechanism of PCDD/Fs. Moreover, the higher $R_{\mathrm{DF} / \mathrm{DD}}$ in this study, as compared to other studies, ${ }^{\mathbf{1 0}, 12}$ indicates that de novo synthesis is more likely to be the dominant formation mechanism of PCDD/Fs in the secondary lead metallurgy. In contrast, the importance of precursor formation and de novo synthesis in the formation of $\mathrm{PCDD} / \mathrm{Fs}$ in the secondary zinc metallurgy is thought to be similar to each other because the ratio of PCDF/ PCDD is close to 1 also with the dominant presence of the lower chlorinated homologue in the stack gas samples. ${ }^{10,12}$

Based on the discussion in section 3.2.2, the congener patterns of dioxin-like PCBs from secondary lead and zinc metallurgies are similar to other thermal processes. It suggests that the formation mechanism of dioxin-like PCBs in the present two kinds of secondary metallurgies and from common thermal sources would be similar. ${ }^{13}$

\subsection{Estimation of PCDD/Fs and dioxin-like PCBs emission factors and total release from secondary zinc and lead metallurgies in China}

The following two equations were used to calculate the emission factors and total release for PCDD/Fs and dioxin-like PCBs:

Emission factor of stack gas (ng TEQ ton ${ }^{-1}$ )

$=\frac{\text { TEQ of PCDD } / \text { Fs or dixoin-like PCBs }\left(\mathrm{ng} \text { TEQ } \mathrm{m}^{-3}\right) \times \text { dry stack gas flow rate }\left(\mathrm{m}^{3} \text { step }^{-1}\right)}{\text { rate of metal production }\left(\text { ton } \mathrm{step}^{-1}\right)}$

Emission factor of fly ash (ng TEQ ton $\left.{ }^{-1}\right)$
$=\frac{\text { TEQ of PCDD } / \text { Fs or dixoin-like PCBs }\left(\text { ng TEQ }^{-1}\right) \times \text { fly ash emisson rate }\left(\mathrm{g} \mathrm{step}^{-1}\right)}{\text { rate of metal production }\left(\text { ton step }^{-1}\right)}$

Total emission amount $\left(\mathrm{g}\right.$ TEQ year $\left.{ }^{-1}\right)=$ emission factor $(\mathrm{ng}$ TEQ ton $^{-1}$ ) $\times$ activity level of reference year (ton year ${ }^{-1}$ )

According to eqn (1) and (2), the TEQ emission factor of $\mathrm{PCDD} / \mathrm{Fs}$ and dioxin-like PCBs released into the air is higher for secondary zinc production, at $52298.02 \mathrm{ng}$ TEQ ton $^{-1}$ than for secondary lead production, at $646.05 \mathrm{ng}$ TEQ ton $^{-1}$. On the other hand, the PCDD/Fs and dioxin-like PCB emission factors released as fly ash from secondary zinc and lead production are calculated to be as low as 246.7 and $30.3 \mathrm{ng}$ TEQ ton ${ }^{-1}$, respectively. Such low emission factors could be attributed to the recycling of the fly ash in the plant for recovering the residual metal inside and the resultant small emission amount of the fly ash per ton of the product.

Subsequently, on the basis of eqn (3), the total emission amounts of PCDD/Fs and dioxin-like PCBs in the secondary zinc and lead metallurgies released to the environment are calculated to be 2.76 (zinc) and $0.42 \mathrm{~g}$ TEQ year $^{-1}$ (lead) where the dioxin-like PCBs take part of $2.8 \%$ (zinc) and $0.6 \%$ (lead) of the total TEQ. These values could be determined to be the minimum emission amount of PCDD/Fs and dioxin-like PCBs released from the secondary zinc and lead metallurgies in China in 2007. The estimation of total emission amounts by emission factors developed in this study is based on the data of medium scale plants with the necessary pollution control equipment. The other smaller-sized plants in the secondary zinc and lead metallurgies in China were usually equipped with the simple and crude devices for the pollution control and could not even fulfill the requirements of isokinetic sampling. Therefore, the emission factors for smaller-scale plants are supposed to be higher than those summarized in this study and result in the higher emission amounts.

\section{Conclusion}

Emission of PCDD/Fs and dioxin-like PCBs from the secondary zinc and lead metallurgies in 2007 in China was evaluated in this study. The emission factor of the secondary zinc production is about 80 times higher than the secondary lead production. The congener patterns of PCDD/Fs from the secondary zinc and lead metallurgies are quite different from each other. Depending on these patterns, the formation mechanism of PCDD/Fs from secondary zinc and lead metallurgies may follow different pathways. For dioxin-like PCBs, the patterns are so similar that the formation mechanism may resemble each other. More investigations on the emission of PCDD/Fs and dioxin-like PCBs for the secondary zinc and lead industry in China need to be performed to obtain further information.

\section{Acknowledgements}

This study was supported by the Chinese Academy of Sciences (Grant No. KZCX2-YW-420), National Natural Science Foundation of China (20677070, 20621703) and National 973 program (2009CB421606).

\section{References}

1 UNEP Chemicals, 2005, Standardized Toolkit for Identification and Quantification of Dioxin and Furan Releases, Edition 2.1, Geneva, Switzerland, available at http://www.pops.int/documents/guidance/ toolkit.

2 H. Fiedler, Chemosphere, 2007, 67, S96-S108.

3 D. R. Anderson and R. Fisher, Chemosphere, 2002, 46, 371-381.

4 C. M. Chen, Chemosphere, 2004, 54, 1413-1420.

5 D. H. Cleverly, Abstr. Pap. Am. Chem. Soc., 2005, 229, U872-U872.

6 R. Lohmann, R. G. M. Lee, J. Abbott, P. Coleman and K. C. Jones, J. Environ. Monit., 2006, 8, 79-88.

7 G. H. Eduljee and P. Dyke, Sci. Total Environ., 1996, 177, 303-321.

8 Department of Foreign Trade of Ministry of Commerce of the Peoples Republic of China, 2008, The performance and policy recommendations for lead industry in China in 2007, Beijing, China, available at http://wms.mofcom.gov.cn/aarticle/subject/gypck/ index.shtml.

9 B. W. Yu, G. Z. Jin, Y. H. Moon, M. K. Kim, J. D. Kyoung and Y. S. Chang, Chemosphere, 2006, 62, 494-501.

10 K. Everaert and J. Baeyens, Chemosphere, 2002, 46, 439-448.

11 P. Luthardt, J. Mayer and J. Fuchs, Chemosphere, 2002, 46, 13031308.

12 L. Stieglitz, H. Bautz, W. Roth and G. Zwick, Chemosphere, 1997, 34, 1083-1090.

13 M. G. Ikonomou, P. Sather, J. E. Oh, W. Y. Choi and Y. S. Chang, Chemosphere, 2002, 49, 205-216. 